\title{
Contagem de Morfotipos de Mobiluncus sp e Concentração de Leucócitos em Esfregaços Vaginais de Pacientes com Vaginose Bacteriana
}

\author{
Mobiluncus sp Morphotype Counts and Leukocyte Concentrations in \\ Vaginal Smears of Patients With Bacterial Vaginosis \\ José Eleutério Junior ${ }^{1}$, Diane Isabelle Magno Cavalcante ${ }^{2}$
}

\begin{abstract}
RESUM0
Objetivos: pesquisar em casos de vaginose bacteriana a presença de bacilos curvos, sugerindo Mobiluncus, e de leucocitose em esfregaços vaginais corados por Gram e Papanicolaou. Métodos: duzentos e cinco pacientes com diagnóstico de vaginose bacteriana pelos Critérios de Amsel foram incluidas e avaliadas clinicamente por um dos autores (JEJ). Os esfregaços vaginais foram corados pelo método de Papanicolaou e avaliados pela técnica de Gram. Nos esfregaços de Gram foram estudados o escore de Nugent e a presença de bacilos curvos. Nos esfregaços de Papanicolaou foi avaliada a presença de bacilos curvos e de leucócitos. Os dados foram analisados usando Prism $3.0^{\circledR}$ com intervalo de confiança de 95\%, usando teste exato de Fisher pelo método modificado de Wald.

Resultados: nos esfregaços de Papanicolaou, bacilos curvos estiveram presentes em 51,7\% das vezes. O número de leucócitos variou, embora a presença de poucos leucócitos tenha sido mais freqüente. Nos esfregaços de Gram, bacilos curvos foram observados em 46,8\% e o escore de Nugent foi $8 \mathrm{em} 48,3 \%$ dos casos. O achado de Mobiluncus sp pelos dois métodos ocorreu em $82 \%$. Na presença de bacilos curvos, maior número de leucócitos foi observado em 57,5\% dos casos ( $p<0,0001)$ e quando o escore de Nugent foi de 9 e 10, a leucocitose ocorreu em 25,6 e 37,2\% das vezes, respectivamente.

Conclusões: bacilos curvos são observados, morfologicamente, em cerca de $52 \%$ dos casos de vaginose bacteriana. Leucocitose é mais observada na presença de Mobiluncus sp e em casos com escores de Nugent mais altos.
\end{abstract}

PALAVRAS-CHAVE: Vaginose bacteriana. Mobiluncus sp. Papanicolaou.

\section{Introdução}

O microambiente vaginal possui uma complexa população, composta por bactérias aeróbias e anaeróbias, que convivem em tênue equilíbrio, e em meio a células esfoliadas, transudatos e exsudatos, conforme estímulos endógenos (niveis hormonais) ou exógenos (coi-

\footnotetext{
${ }^{1}$ Serviço de Patologia do Trato Genital Inferior e Colposcopia - Maternidade Escola Assis Chateaubriand e Departamento de Análises Clínicas e Toxicológicas - Universidade Federal do Ceará

${ }^{2}$ Laboratório LABPEC ${ }^{\circledR}$ - Fortaleza - CE

Correspondência:

José Eleutério Junior

Rua Tenente Benévolo 1560/202 - Aldeota

60160-041 - Fortaleza - CE

Fone/Fax: (85) 253-0100

e-mail:dr.eleuterio@zipmail.com.br
}

to, uso de substâncias intravaginais, dispositivo intra-uterino, etc.) ${ }^{1}$.

Vaginose bacteriana é considerada uma sindrome que primariamente envolve desequilíbrio da microbiota vaginal com mudança da população bacteriana predominantemente aeróbia (Lactobacillus sp), da vagina normal, para anaeróbia (Gardnerella vaginalis, Prevotella sp, Bacteroides sp, Mobiluncus sp e Peptostreptococcus $\mathrm{sp})^{2,3}$. As razões para este desequilíbrio são desconhecidas, embora a perda de lactobacilos produtores de peróxido de hidrogênio, que é tóxico para numerosos anaeróbios, deva ser elemento essencial ${ }^{3}$.

Em 1983, Amsel et al. ${ }^{4}$ criaram critérios que passaram a ser adotados para o diagnóstico da condição, levando-se em conta não um único teste, mas um conjunto de achados que, associados, con- 
firmariam o diagnóstico de uma doença caracterizada por um conjunto de sinais e sintomas. Assim, a relação exclusiva de Gardnerella vaginalis como agente causal da vaginose foi abandonada, uma vez que a palavra bacteriana especifica a multiplicidade de bactérias envolvidas.

Dentre as bactérias identificadas nos quadros de vaginose bacteriana estão aquelas do gênero Mobiluncus, que são bacilos curvos, anaeróbios e com mobilidade. Vários estudos têm demonstrado a sua presença na vaginose bacteriana, associada a Gardnerella vaginalis, com variável prevalência (de 65 a 85\%) ( $^{5-9}$, conforme a metodologia usada para a sua identificação.

Dentre os métodos diagnósticos considerase ser o método de Papanicolaou de menor sensibilidade, embora tenha razoável especificidade, para o diagnóstico da vaginose bacteriana, bem como para identificação de morfotipos de Mobiluncus sp. Entrementes, a bacterioscopia por Gram tem mostrado excelente sensibilidade, possibilitando o diagnóstico do desequilíbrio bacteriano sem necessidade de outros parâmetros, por escore de Nugent et al. ${ }^{10}$.

O objetivo do presente estudo foi identificar a presença de morfotipos sugestivos de Gardnerella vaginalis e Mobiluncus sp em esfregaços vaginais corados por Gram, comparando-a com outros corados por método de Papanicolaou, bem como de leucocitose nos exames de Papanicolaou e Gram em casos de vaginose bacteriana, levando-se em conta os critérios de Amsel et al. ${ }^{4}$ e o escore de Nugent et al. ${ }^{10}$.

\section{Pacientes e Métodos}

De janeiro de 2002 a março de 2003, foram investigadas duzentas e cinco pacientes que, segundo a avaliação clínica de um dos autores (JEJ), preenchiam critérios de Amsel et al. ${ }^{4}$ (Tabela 1), ou seja, havia referência de corrimento homogêneo, odor fétido com o uso de $\mathrm{KOH}$ a $10 \%$ e $\mathrm{pH}$ vaginal alcalino. A idade variou entre 20 e 45 anos (média de 32 anos). Todas referiam ciclos menstruais e atividade sexual. Foram submetidas à colheita de conteúdo vaginal para confecção de dois esfregaços. Um destes foi fixado a seco para posterior coloração pelo método de Gram e um segundo foi fixado em álcool a 95\% para posterior coloração pelo método de Papanicolaou.

Foram considerados critérios para exclusão: associação do quadro com outros patógenos e lesões intra-epiteliais escamosas, pós-menopausa, gravidez e uso de medicamentos sistêmicos ou tópicos, bem como condições de imunodepressão (transplante renal, quimioterapia, AIDS, etc.) ou dispositivos com finalidade contraceptiva.

Tabela 1 - Critérios diagnóstico de Amsel et al. ${ }^{4}$ para vaginose bacteriana.

1. Corrimento homogêneo e fino

2. Teste das aminas (teste do $\mathrm{KOH} 10 \%$ ) positivo

3. Bacilos supracitoplasmáticos sugestivos de Gardnerella vaginalis/ Mobiluncus sp na microscopia

4. $\mathrm{pH}$ vaginal $>4.5$

Ocorrendo três de quatro critérios observados, pode-se estabelecer o diagnóstico de vaginose bacteriana em $90 \%$ das mulheres acometidas

Os esfregaços corados pelo Gram foram avaliados em microscópio óptico em aumento de 1000 vezes, com a finalidade de observação da microbiota vaginal, para que os achados foram submetidos ao método de escore de Nugent et al. ${ }^{10}$. A metodologia consiste em se identificarem bacilos Gram(+) (sugestivos de lactobacilos), bacilos curtos Gram-variáveis (sugestivos de Gardnerella vaginalis) e bacilos curvos Gram(-) ou variáveis (sugestivos de Mobiluncus sp). Conforme a ausência ou presença de cada morfotipo se dá pontuação que ao final é somada. Serão consideradas como vaginose bacteriana situações em que o escore seja de sete ou mais (Tabela 2). Não se tentou, por morfologia, diferenciar as espécies.

Tabela 2 - Critérios diagnósticos de Nugent et al. ${ }^{10}$ para vaginose bacteriana.

A. Lactobacillus acidophilus (bacilos Gram-positivos)

B. Gardnerella vaginalis e espécies bacteróides (bacilos curtos Gram-variáveis)

C. Mobiluncus sp (bacilos curvos Gram-negativos ou variáveis)

O escore total é a soma do peso da quantidade dos três morfotipos bacterianos.

Escore para cada um dos morfotipos

Zero $=$ sem morfotipos no campo de imersão (1000X)

$1+=$ menos que um morfotipo por campo de imersão (1000X)

$2+=$ um a quatro morfotipos por campo de imersão (1000X)

$3+=$ cinco a trinta morfotipos por campo de imersão (1000X)

$4+=$ mais que trinta morfotipos por campo de imersão (1000X)

A soma dos pontos dá o escore final, ou seja, $A+B+C$ :

0 a $3=$ normal.

4 a $6=$ intermediário.

7 a $10=$ vaginose bacteriana.

Nos esfregaços de Papanicolaou procurou-se observar, em microscópio óptico com aumento de 1000 vezes, a presença de bacilos curvos, não necessariamente apenas na forma de "células cabeludas", mas também no fundo do esfregaço. Além 
disso, contabilizou-se a presença de leucócitos empregando-se os escores 0 (zero) quando observadas menos que duas unidades por célula escamosa; 1+ para 2-4 unidades por célula escamosa; 2+ para 5-8 unidades por célula escamosa e 3+ para mais de 8 unidades por célula escamosa. Foi também avaliada a presença de alterações celulares degenerativas, que denunciariam quadro citológico inflamatório, mesmo com clinica de vaginose bacteriana. Quadros contabilizados como $2+$ ou $3+$ foram considerados como leucocitose.

O escore de Nugent et al. ${ }^{10}$ (confirmando o quadro clínico de vaginose bacteriana pelos critérios de Amsel et al. ${ }^{4}$ ) e a presença de bacilos curvos na bacterioscopia (sugerindo Mobiluncus) foram confrontados com quadro citológico não inflamatório (vaginose citológica, quadro de vaginose com esfregaços com escassos leucócitos) ou inflamatório (vaginite citológica, quadro de vaginose bacteriana com infiltrado leucocitário) no método de Papanicolaou.

Os dados foram analisados estatisticamente por meio do programa Prism $3.0^{\circledR}$ e adotando-se intervalo de confiança de 95\%, usando-se teste exato de Fisher pelo método de Wald modificado para comparação entre os métodos de Papanicolaou e Gram no diagnóstico de bacilos curvos sugestivos de Mobiluncus sp na vaginose bacteriana e para a avaliação de representação de leucócitos nos esfregaços estudados, conforme a presença ou não dos bacilos curvos Gram (-).

O projeto foi avaliado e aprovado pelo Comitê de Ética da Universidade Federal do Ceará.

\section{Resultados}

$\mathrm{Na}$ avaliação dos esfregaços vaginais corados pelo método de Papanicolaou, observou-se presença de bacilos curvos, sugestivos de Mobiluncus $\mathrm{sp}$, em $51,7 \%$ dos casos de vaginose bacteriana.

Os esfregaços submetidos ao método de Gram evidenciaram a presença dos bacilos curvos Gram negativos em $46,8 \%$ dos casos de vaginose bacteriana, diagnosticada pelos critérios de Amsel et al. ${ }^{4}$ e escore de Nugent et al. ${ }^{10}$. Avaliados pelo escore de Nugent et al. ${ }^{10}$ todos os casos ficaram com indices entre 7 e 10, com maior proporção de casos com escore $8(48,3 \%)$ e 10 $(29,3 \%)$. Tal escore, quando da presença de bacilos curvos Gram-negativos, foi quantificado, somando-se os demais morfotipos e a ausência de lactobacilos, predominantemente como $10(50,6 \%)$ e $9(28,3 \%)(p<0,05)$ (Tabela 3$)$.

\begin{tabular}{|c|c|c|c|}
\hline \multirow[t]{2}{*}{ Escore } & \multicolumn{3}{|c|}{ Bacilos curvos Gram-negativos } \\
\hline & $\begin{array}{l}\text { Presentes } \\
\text { n (\%) }\end{array}$ & $\begin{array}{c}\text { Ausentes } \\
\text { n (\%) }\end{array}$ & $\mathrm{p}$ \\
\hline 7 & $9 \quad(8,4)$ & $5(5,0)$ & $\neq 0.2854$ \\
\hline 8 & $7 \quad(6,6)$ & $94(94,9)$ & $<0.0001$ \\
\hline 9 & $30(28,3)$ & - & $<0.0001$ \\
\hline 10 & $60(50,6)$ & - & 0.0001 \\
\hline Total & $105(100)$ & $99(100)$ & \\
\hline
\end{tabular}

Significância estatística $-p<0,05$

A identificação dos bacilos sugestivos de Mobiluncus sp pelos dois métodos mostrou concordância de $82 \%$. Quando foi levada em conta a presença dos bacilos curvos (no Papanicolaou), os casos com leucocitose predominaram $(70,9 \%)$ sobre os casos sem leucocitose $(37,8 \%)$, ao passo que na ausência de bacilos curvos predominaram casos sem leucocitose $(62,2 \%)$, portanto com diferença significante $(\mathrm{p}<0,05)$ (Tabela 4). A presença de leucocitose apresentou diferenças quando se levavam em conta os escores de Nugent et al. ${ }^{10}$. Nos casos com escore 7 não houve diferença significativa entre a quantidade maior ou menor de leucócitos $(p=0,1662)$. Entre os classificados com escore 8 predominou a ausência da leucocitose $(\mathrm{p}<0,05)$ ao passo que com escore 9 predominou a leucocitose $(p<0,05)$. No entanto, no escore 10 não houve diferença significativa $(\mathrm{p}=0,0649)($ Tabela 5).

Tabela 4 - Infiltrado leucocitário em esfregaços vaginais corados por método de Papanicolaou, conforme a presença de bacilos curvos Gram-negativos, em casos de vaginose bacteriana $(n=205)$.

\begin{tabular}{lccc}
$\begin{array}{l}\text { Número de } \\
\text { leucócitos } \\
\text { (Papanicolau) }\end{array}$ & Bacilos curvos Gram-negativos & \\
& $\begin{array}{c}\text { Presentes } \\
\mathbf{n ~ ( \% )}\end{array}$ & $\begin{array}{c}\text { Ausentes } \\
\mathbf{n}(\%)\end{array}$ & $\mathbf{p}$ \\
\hline 0 & $22(20,7)$ & $34(34,3)$ & 0,0415 \\
$1+$ & $23(21,7)$ & $40(40,4)$ & 0.0091 \\
$2+$ & $30(28,3)$ & $16(16,1)$ & 0.0427 \\
$3+$ & $31(29,2)$ & $9(9,0)$ & 0.0003 \\
Total & $106(100)$ & $99(100)$ &
\end{tabular}

Significância estatística $-p<0,05$ 
Tabela 5 - Leucocitose observada em esfregaços vaginais de casos de vaginose bacteriana corados pelo método de Papanicolaou em relação ao escore de Nugent et al. ${ }^{10}$ avaliado em esfregaços corados por método de Gram $(n=205)$.

\begin{tabular}{cccc}
\hline $\begin{array}{c}\text { Escores de } \\
\text { Nugent }\end{array}$ & $\begin{array}{c}\text { Com leucocitose } \\
\mathbf{n}(\%)\end{array}$ & $\begin{array}{c}\text { Sem leucocitose } \\
\mathbf{n}(\%)\end{array}$ & $\mathbf{p}$ \\
\hline 7 & $3(3,8)$ & $11(8,6)$ & 0.1662 \\
8 & $26(33,3)$ & $75(59,0)$ & 0.0002 \\
9 & $20(25,6)$ & $10(7,8)$ & 0.0007 \\
10 & $29(37,1)$ & $31(24,4)$ & 0.0649 \\
Total & $78(100)$ & $127(100)$ & \\
\hline
\end{tabular}

Significância estatística - $p<0,05$

\section{Discussão}

De forma geral, a presença de Mobiluncus sp foi sugerida em $51,7 \%$ dos casos pelo exame de Papanicolaou e em $46,8 \%$ pelo método de Gram. Conforme achados de Hellberg et al. ${ }^{9}$, a presença de morfotipos sugestivos de Mobiluncus sp, pesquisados em exame a fresco, em casos de vaginose bacteriana, foi de $65,7 \%$, contra $30,7 \%$ em mulheres sem vaginose bacteriana ${ }^{9}$. Schwebke and Lawing 6 , usando PCR (polymerase chain reaction), observaram Mobiluncus sp em $84,5 \%$ dos casos de vaginose bacteriana e $38 \%$ dos casos sem vaginose bacteriana. No presente estudo houve concordância de $82 \%$ entre os dois métodos, semelhante ao que demonstraram Mota et al. ${ }^{8}$.

O método de Gram e o exame de Papanicolaou têm demonstrado ter sensibilidade de 94,7 e 98\% para diagnóstico de vaginose bacteriana, respectivamente $^{11,12}$. A sensibilidade para detecção de Mobiluncus sp pelo Gram foi previamente demonstrada ser de $84 \%$, comparável à cultura e a pesquisa com uso de anticorpo monoclonal ${ }^{6}$. Comparada à PCR, a sensibilidade do Gram foi de 46,9\%, mas a especificidade foi de $100 \%{ }^{6}$. Com o uso de PCR tem-se observado associação de presença de Mobiluncus de $38,3 \%$ até $84,5 \%$ nos casos de vaginose $^{5,6}$. Assim, podemos afirmar que a identificação de morfotipos de Mobiluncus sp pelo Gram em $46,8 \%$ dos casos de vaginose bacteriana é plausivel e concordante com achados dos estudos acima citados. Dessa forma, a observação de concordância diagnóstica com o Papanicolaou em $82 \%$ das vezes permite afirmar que, diante de uma pesquisa direcionada, utilizando-se a objetiva de imersão do microscópio (aumento de 1000 vezes) é possível ter a identificação do bacilo curvo na vaginose bacteriana.

A esperada leucopenia ${ }^{13}$ nos casos de vaginose bacteriana não foi constante, principal- mente quando se observou a presença de Mobiluncus sp nos espécimes; nesta situação houve leucocitose em maior número de casos. Assim, a visualização morfológica de Mobiluncus sp, quer no Gram, quer no Papanicolaou, esteve associada, com mais freqüência, à leucocitose. Embora a inibição da quimiotaxia produzida pelo ácido succínico e, em menor escala, pelo ácido acético possa ocorrer nos casos de anaerobiose vaginal, principalmente associados a Prevotella e Mobiluncus ${ }^{13}$, mais complexas correlações, envolvendo citocinas, impedem que haja constância da associação entre a população microbiológica e a leucopenia ${ }^{1}$. Tal fato traz uma controvérsia recentemente levantada por Demirezen ${ }^{14}$ de que os casos com leucocitose, portanto, citologicamente uma vaginite, não deveriam ser considerados realmente uma vaginose. Somos obrigados a discordar destas conclusões, uma vez que nem os critérios de Amsel et al. ${ }^{4}$, nem o escore de Nugent et al. ${ }^{10}$, que são adotados para o diagnóstico da condição, levam em conta a concentração de leucócitos nos esfregaços vaginais.

A avaliação do escore de Nugent et al. ${ }^{10} \mathrm{com}-$ provou todos os casos de vaginose e mostrou-se com contagem predominantemente maior nos casos em que bacilos curvos Gram-negativos estavam presentes. Conforme tem sido demonstra$\mathrm{do}^{7}, 11 \%$ das mulheres com diagnóstico de vaginose bacteriana pelos critérios de Amsel et al. ${ }^{4}$ não têm diagnóstico comprovado pelo Gram e, em contrapartida, 30\% daquelas com vaginose bacteriana pelo escore de Nugent et al. ${ }^{10}$ têm achados negativos pelos critérios de Amsel et al. ${ }^{4}$. Assim, justifica-se o uso concomitante dos dois métodos para um diagnóstico não contestável de vaginose bacteriana. Foi interessante observar também que escore de Nugent et $a .^{10}$ nos seus extremos não mostra diferença na concentração leucocitária, ao contrário dos escores 8 e 9 em que se observa diferença significante quanto a ocorrências de leucocitose.

Com os achados do presente trabalho podese concluir a condição na qual se observa a vaginose bacteriana, confirmada pelos dois métodos (Amsel et al. ${ }^{4}$ e Nugent et al. ${ }^{10}$ ), é a que tem a presença de bacilos curvos (sugestivos de Mobiluncus sp) pela coloração do Papanicolaou e de Gram, em 51,7 e 46,8\%, respectivamente, com uma concordância entre os métodos de $82 \%$. Ao mesmo tempo, a presença de leucocitose nos esfregaços de Papanicolaou estaria mais relacionada à presença de Mobiluncus sp. Tais achados demonstram a complexidade que caracteriza essa condição, que está longe de estar inteiramente esclarecida em sua gênese e sua fisiopatologia. 


\section{ABSTRACT}

Objective: to evaluate the presence of curved rods, suggesting Mobiluncus sp, and leukocytosis on Gram and Papanicolaoustained vaginal smears in cases of bacterial vaginosis. Methods: two hundred and five vaginal smears were studied by the Papanicolaou's method and other 205 vaginal smears, in the same patients, were evaluated by Gram staining. The diagnosis of bacterial vaginosis was made clinically by one of the authors (J.E.J.) using Amsel's criteria. In the Gram method stained smears the Nugent's score was calculated and the presence of curved rods was evaluated. In Papanicolaou's smears curved rods were searched as well the presence of leukocytes. The data were analyzed by Prism $3.0^{\circledR}$ with confidence interval of $95 \%$ using the Fisher exact test with modified Wald's method.

Results: on Pap smears the curved rods were present in $51.7 \%$ of the cases. The number of leukocytes varied, although the leukopenia was more frequent. In Gram-stained smears the curved rods were present in $46.8 \%$ of the cases and the Nugent's score was 8 in $48.3 \%$ of the cases. The finding of Mobiluncus sp in both methods occurred in $82 \%$. When curved rods were observed leukocytosis occurred in $57.5 \%$ $(p<0.0001)$. In the same way, leukocytosis was more frequent in Nugent's scores 9 and 10.

Conclusion: curved rods were observed in about $52 \%$ of bacterial vaginosis. Leukocytosis in Pap smears was more frequent when Mobiluncus sp were found with higher Nugent's scores.

KEY WORDS: Bacterial vaginosis. Mobiluncus sp. Papanicolaou stain.

\section{Referências}

1. Donders GG, Bosmans E, Dekeersmaecker A, Vereecken A, Van Bulck B, Spitz B. Pathogenesis of abnormal vaginal bacterial flora. Am J Obstet Gynecol 2000; 182:872-8.

2. Delaney ML, Onderdonk AB. Nugent score related to vaginal culture in pregnant women. Obstet Gynecol 2001; 98:79-84.
3. Calzolari E, Masciangelo R, Milite V, Verteramo R. Bacterial vaginosis and contraceptive methods. Int J Gynaecol Obstet 2000; 70:341-6.

4. Amsel R, Totten PA, Spiegel CA, Chen KC, Eschenbach DA, Holmes KK. Nonspecific vaginitis: diagnostic criteria and microbial and epidemiologic associations. Am J Med 1983; 74:14-22.

5. Hellberg D, Nilsson S, Mardh PA. The diagnosis of bacterial vaginosis and vaginal flora changes. Arch Gynecol Obstet 2001; 265:11-5.

6. Schwebke JR, Lawing LF. Prevalence of Mobiluncus spp among women with and without bacterial vaginosis as detected by polymerase chain reaction. Sex Transm Dis 2001;28:195-9.

7. Schwebke JR. Asymptomatic bacterial vaginosis: response to therapy. Am J Obstet Gynecol 2000; 183:1434-9.

8. Mota A, Prieto E, Carnall V, Exposto F. Avaliação de métodos microscópicos para diagnóstico de vaginose bacteriana. Acta Med Port 2000; 13:77-80.

9. Hellberg D, Nilsson S, Mardh PA. Bacterial vaginosis and smoking. Int J STD AIDS 2000; 11:603-6.

10.Nugent RP, Krohn MA, Hillier SL. Reliability of diagnosing bacterial vaginosis is improved by a standardized method of gram stain interpretation. J Clin Microbiol 1991; 29:297-301.

11.Almeida GM, Eleutério Junior J. Vulvovaginite na infância e adolescência: análise de 1107 exames citológicos. Rev Bras Ginecol Obstet 1997; 19:111-6.

12.Fan S, Ke Y, Li Q. Detection of bacterial vaginosis in gram stained vaginal smears and Papanicolaou stained cervical smears [abstract]. Zhonghua Yi Xue Za Zhi 1996;76:284-6.

13.Al-Mushrif S, Eley A, Jones BM. Inhibition of chemotaxis by organic acids from anaerobes may prevent a purulent response in bacterial vaginosis. J Med Microbiol 2000; 49:1023-30.

14.Demirezen S. Review of cytologic criteria of bacterial vaginosis: examination of 2,841 Papanicolaou stained vaginal smears. Diagn Cytopathol 2003; 29:156-9. 